\title{
Modeling the transition state structure to probe a reaction mechanism on the oxidation of quinoline by quinoline 2-oxidoreductase
}

\author{
Enyew A. Bayle*
}

\begin{abstract}
Background: Quinoline 2-oxidoreductase (Qor) is a member of molybdenum hydroxylase which catalyzes the oxidation of quinoline (2, 3 benzopyridine) to 1-hydro-2-oxoquinoline. Qor has biological and medicinal significances. Qor is known to metabolize drugs produced from quinoline for the treatment of malaria, arthritis, and lupus for many years. However, the mechanistic action by which Qor oxidizes quinoline has not been investigated either experimentally or theoretically.
\end{abstract}

Purpose of the study: The present study was intended to determine the interaction site of quinoline, predict the transition state structure, and probe a plausible mechanistic route for the oxidative hydroxylation of quinoline in the reductive half-reaction active site of Qor.

Results: Density functional theory calculations have been carried out in order to understand the events taking place during the oxidative hydroxylation of quinoline in the reductive half-reaction active site of Qor. The most electropositivity and the lowest percentage contribution to the $\mathrm{HOMO}$ are shown at $\mathrm{C}_{2}$ of quinoline compared to the other carbon atoms. The transition state structure of quinoline bound to the active site has been confirmed by one imaginary negative frequency of $-104.500 / \mathrm{s}$ and $-1.2365899 \mathrm{E}+06$ transition state energies. The Muliken atomic charges, the bond distances, and the bond order profiles were determined to characterize the transition state structure and the reaction mechanism.

Conclusion: The results have shown that $C_{2}$ is the preferred locus of interaction of quinoline to interact with the active site of Qor. The transition state structure of quinoline bound to the active site has been confirmed by one imaginary negative frequency. Moreover, the presence of partial negative charges on hydrogen at the transitions state suggested hydride transfer. Similarly, results obtained from total energy, iconicity and molecular orbital analyses supported a concerted reaction mechanism.

Keywords: Quinoline, Interaction site, Quinoline 2-oxidoreductase, Reaction mechanism

\section{Background}

Quinoline 2-oxidoreductase is a member of molybdenum hydroxylases with a known three dimensional structure [1]. It catalyzes the oxidative hydroxylation of quinoline (2, 3 benzopyridine) to 1-hydro-2-oxoquinoline. Qor is known to oxidatively hydroxylate carbon atoms of heterocyclic aromatic compounds, particularly quinoline and

\footnotetext{
*Correspondence: enyewalemayehu@gmail.com Department of Chemistry, College of Natural and Computational Science, Haramaya University, Harar, Ethiopia
}

its derivatives. For instance, it catalyzes the first two steps in the degradation of quinoline in bacteria (Comamonas testosteroni 63) [2]. Quinoline derivatives have been used in the treatments of malaria, arthritis, and lupus for many years [3]. They are also used as a sole source of energy in bacteria [1], hepatocarcinogen in mice and rats, and several quinoline derivatives are mutagens [4]. However, quinoline derivatives are known to represent one of the most successfully used classes of drugs, their therapeutic action is still not well understood. Remarkably, there is no clear catalytic mechanism known for the therapy 
of action of quinoline drugs [3]. Therefore, the catalytic mechanism of Qor needs to be investigated in order to improve the use of quinoline in the drug design process.

All molybdenum enzymes contain the molybdenum cofactor in common. The molybdenum cofactor is the reductive half-reaction active site of Qor [5]. It is composed of a $\mathrm{Mo}^{(+\mathrm{VI})}$ ion and a molybdopterin cytosine dinucleotide [5]. All ligands coordinated with molybdenum ion are inorganic ligands and the coordination adopts a distorted coordination sphere [1] (Fig. 1). It is labile in nature and highly sensitive to air oxidation as a result the chemical syntheses of either Moco or its intermediates have never been successful so far [5].

It was already known that molybdenum hydroxylases oxidatively hydroxylate their substrates at the electron deficient carbon center adjacent to nitrogen atom [6]. But, in the case of the oxidative hydroxylation reactions catalyzed by Qor, there are two ideas regarding to the interaction site of quinoline that interacts with the hydroxyl oxy-anion of the active site of Qor. Quinoline is proposed to have two interaction sites (Fig. 2). Some papers supported that quinoline interacts with its $\mathrm{C}_{2}$ with the active site $[1,2]$. On the contrary, other investigations argued that quinoline interacts with the active site at its $\mathrm{C}_{4}$ position [6]. This discrepancy draws attention to probe the interaction site of quinoline. The overall reaction mechanism catalyzed by Qor is given in Eq. (1).

$$
\mathrm{RH}+\mathrm{H}_{2} \mathrm{O} \leftrightarrow \mathrm{ROH}+2 \mathrm{H}^{+}+2 e^{-}
$$

where, $\mathrm{R}$ is the heterocyclic aromatic compounds [7]. Although some of the substrates and the corresponding products of the reaction catalyzed by Qor are known [6], the catalytic conversions of the reactants into the products and the events that are expected to takes place have never been described.

Qor catalyzes similar substrates with the enzyme Xanthine oxidoreductase (XOR) [6]. Quinoline, physiological substrates of Qor, and xanthine, physiological

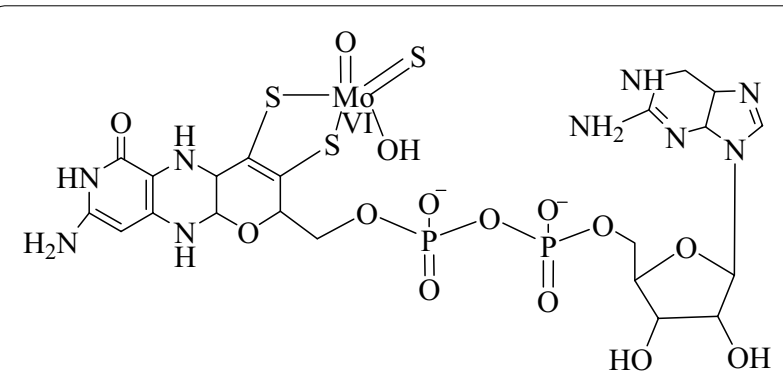

Fig. 1 The chemical structure of the molybdenum cofactor (reductive half reaction) found in Qor Adopted from Ref. [1]

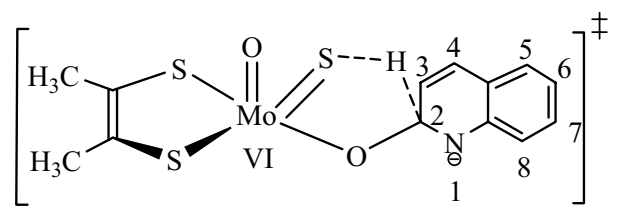

Fig. 2 The general tetrahedral model structure used for predicting a transition state structure of the truncated Moco bound to quinoline, the numbers indicate the position of carbon atoms on quinoline

substrates of XOR, share some common features such as both are an aromatic compounds with two ring systems. Moreover, Qor and XOR are the members of molybdenum hydroxylases particularly xanthine oxidase family enzymes and hence basically they have similar redox active centers $[7,8]$. For this reason the catalytic mechanisms of Qor is expected to be studied on the basis of the catalytic mechanisms of XOR [1]. XOR from bovine milk is the most studied members of molybdenum hydroxylase. Consequently, it can be used as a bench mark to study the entire members of Mo hydroxylase such as Qor [9]. Based on the currently accepted catalytic mechanisms of XOR [10], the catalytic mechanism of Qor is proposed in the study.

The reaction mechanism is proposed to begin with the abstraction of the equatorial hydroxyl proton by the amino acid residue (Glu743). The neucleophile, oxy-anion of the hydroxyl group, attacks the electron deficient carbon center of the substrate and provides a tetrahedral species (tetrahedral intermediate or transition state). At the transition state hydrogen is transferred from the substrate carbon to the sulfido terminal of the active site [11]. However, it not known whether oxidative hydroxylation of quinoline catalyzed by Qor is concerted or stepwise. In addition to that the mechanism of a catalytic reaction can be characterized in terms of the chemical events that take place during the reaction [12]. However, several events that are expected to occur during the oxidation of quinoline such as formation of a bond between the equatorial oxygen and the quinoline carbon, cleavage of quinoline carbon-hydrogen bond, migration of hydrogen from quinoline carbon to the sulfido terminal of the active site, and conversion of quinoline to 1-hydro-2-oxoquinoline were neither known nor described. Moreover the nature of hydrogen transfer from the substrate carbon to the sulfido terminal of Qor is not known.

In order to probe either the concerted or stepwise mechanism, Scheme 1 is proposed for the oxidation of quinoline catalyzed by Qor. This hypothetical schematic model is expected to pass through the transition state structure (structured) for both the stepwise (route I) and 


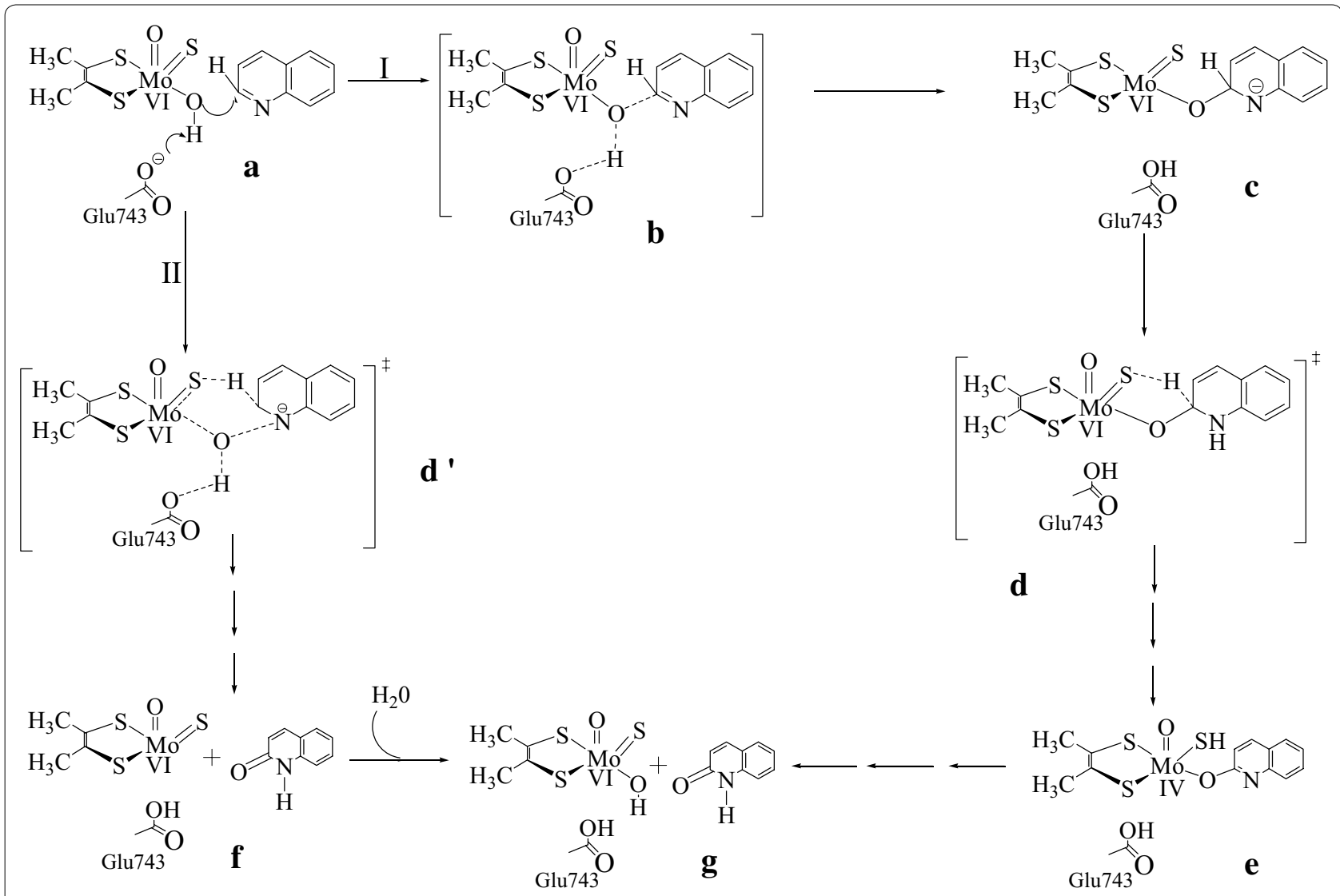

Scheme 1 The hypothetical schematic model used to probe whether the catalytic oxidative hydroxylation of quinoline by Qor is stepwise (route, I) or concerted (route, II) Adapted from Ref. [10]

concerted (route II) reaction mechanism. Moreover, at the transition state structure, hydrogen and electrons are expected to be transferred from the substrate carbon $\left(\mathrm{C}_{\mathrm{RH}}\right)$ to the sulfido terminal $\left(\mathrm{S}_{\mathrm{Mo}}\right)$ of the active site. However, the natures of proton and electrons transfer were not described.

A density functional theory approach was designed to perform electronic structure calculations in order to investigate the catalytic mechanism and describe the events those are expected to take place during the catalytic oxidative hydroxylation of quinoline by Qor. The calculations were performed on the truncated active site model compound bound to quinoline. From the optimized structures several data such as total energies, Mulliken atomic charges, bond distance, bond order indices, and percentage contributions of the chemical constituents to the molecular orbitals were generated. These data were used to determine the interaction site of quinoline, model the transition state structure, and probe a plausible mechanistic route for the oxidative hydroxylation of quinoline in the reductive half-reaction active site of Quinoline 2-oxidoreductase.

\section{Computational methods}

The electronic structure calculations were performed with density functional theory method on the Gaussian ${ }^{\circledR}$ $03 \mathrm{~W}$ (version 6.0) program software package (Gaussian, Inc., Wallingford, CT, USA) [13]. The DFT method employing the B3LYP level of theory [14] was applied on the model structures derived from the initial geometries of the crystal structures of Qor [1]. The optimizations were carried out using the mixed basis set LANL2DZ for Mo which contains core potential (LanL2), and 6-31G $\left(\mathrm{d}^{1}-\mathrm{p}^{1}\right)$ basis set for $\mathrm{C}, \mathrm{N}, \mathrm{O}$ and $\mathrm{S}$ [15].

The substrate quinoline and quinoline bound to the truncated reductive half-reaction active site of Qor at $\mathrm{C}_{2}$ and $\mathrm{C}_{4}$ position of quinoline were optimized in order to identify the interaction site of quinoline. The transition state structure was determined for the migration of substrate bound $\left(\mathrm{H}_{\mathrm{RH}}\right)$ from the substrate carbon $\left(\mathrm{C}_{\mathrm{RH}}\right)$ to the sulfido terminal $\left(\mathrm{S}_{\mathrm{Mo}}\right)$. The linear transit scans were performed on the structure shown on Fig. 2.

The transition state structure was located by the presence of one imaginary negative frequency [16]. The geometries from single point energy calculations were 
used for AOMix molecular analysis using AOMix 2011/2012 (reversion 6.6) software programs [17, 18]. The total energies and the Muliken atomic charges were generated from the optimized geometries of single point energy calculations. The total energies were normalized in order to profile the reaction coordinates.

Moreover, the mechanistic routes for the oxidative hydroxylation of quinoline by Qor were probed by performing a series of geometry optimizations on the geometries shown in Scheme 2. The mechanistic routes were analyzed by describing the bonds that were formed and broken in terms of Muliken atomic charges, bond lengths, bond order indices, and the percentage contribution of the chemical constituents of to the molecular orbitals.

\section{Results and discussion}

\section{Probing the interaction site of quinoline}

The Mulliken atomic charges on the carbon atoms of the unbound quinoline were calculated (Fig. 3). Accordingly, the data revealed the unique nature of one of the carbon atoms, $\mathrm{C}_{2}$, located in the pyridine ring. The $\mathrm{C}_{2}$-pyridine was shown to bear partial positive charges (0.025), the only atom with an electropositive charge. Unlike to this carbon atom, the remaining carbon atoms (in the benzopyridine ring) were shown to bear partial positive charges. According to the principle of nucleophilic/ electrophilic reaction, nucleophiles prefer to attack the most electrons deficient species (carbon centers, in quinoline). Moreover, $\mathrm{C}_{2}$ and $\mathrm{O}_{\text {eq }}$ are oppositely charged which enables the equatorial oxygen to easily donate a pair of electrons to carbon $\left(\mathrm{C}_{2}\right)$, an electrophile, to form a bond $\left\{\left[\mathrm{Mo}^{(+\mathrm{VI})}\right] \mathrm{O}_{\mathrm{eq}}-\mathrm{C}_{2}\right.$-pyridine $\}$.

Similarly, the percentage contributions of the carbon atoms to the highest occupied molecular orbital (HOMO) of unbound (free) quinoline were calculated (Fig. 4). Accordingly, the lowest contribution to the HOMO is shown at $\mathrm{C}_{2}$-pyridine of quinoline. This reflects that the electron density on $\mathrm{C}_{2}$-pyridine is the lowest among the carbon atoms of unbound (free) quinoline. Even if the contribution on $\mathrm{C}_{2}$-pyridine is about $50 \%$ less than $\mathrm{C}_{3}$-pyridine, the preferred interaction site remains $\mathrm{C}_{2}$-pyridine.

Moreover, the total energies obtained from optimization for $\mathrm{C}_{2}$-quinoline or $\mathrm{C}_{4}$-quinoline bound to the active site $\left(\mathrm{Mo}^{(+\mathrm{VI})}-\mathrm{O}_{\mathrm{eq}}-\mathrm{C}_{2}-\right.$ quinoline or $\mathrm{Mo}^{(+\mathrm{VI})}-\mathrm{O}_{\mathrm{eq}}-\mathrm{C}_{4}-$ quinoline, respectively) are $(-1.23661074 \mathrm{E}+06)$ and $(-1.23661438 \mathrm{E}+06) \mathrm{kcal} / \mathrm{mol}$, respectively. These results clearly show that the active site bound at $\mathrm{C}_{2}$ position of quinoline is destabilized by $3.64 \mathrm{kcal} / \mathrm{mol}$ relative to the active site bound at $\mathrm{C}_{4}$ position of quinoline. This indicates that the active site bound at $\mathrm{C}_{2}$ position of quinoline exhibits lower energy barrier to enter the transition state compared to the active site bound at $C_{4}$ position of quinoline.

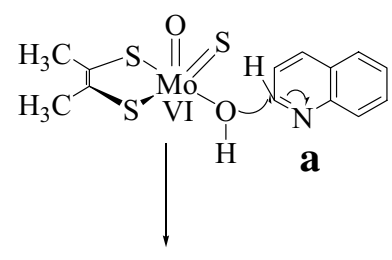

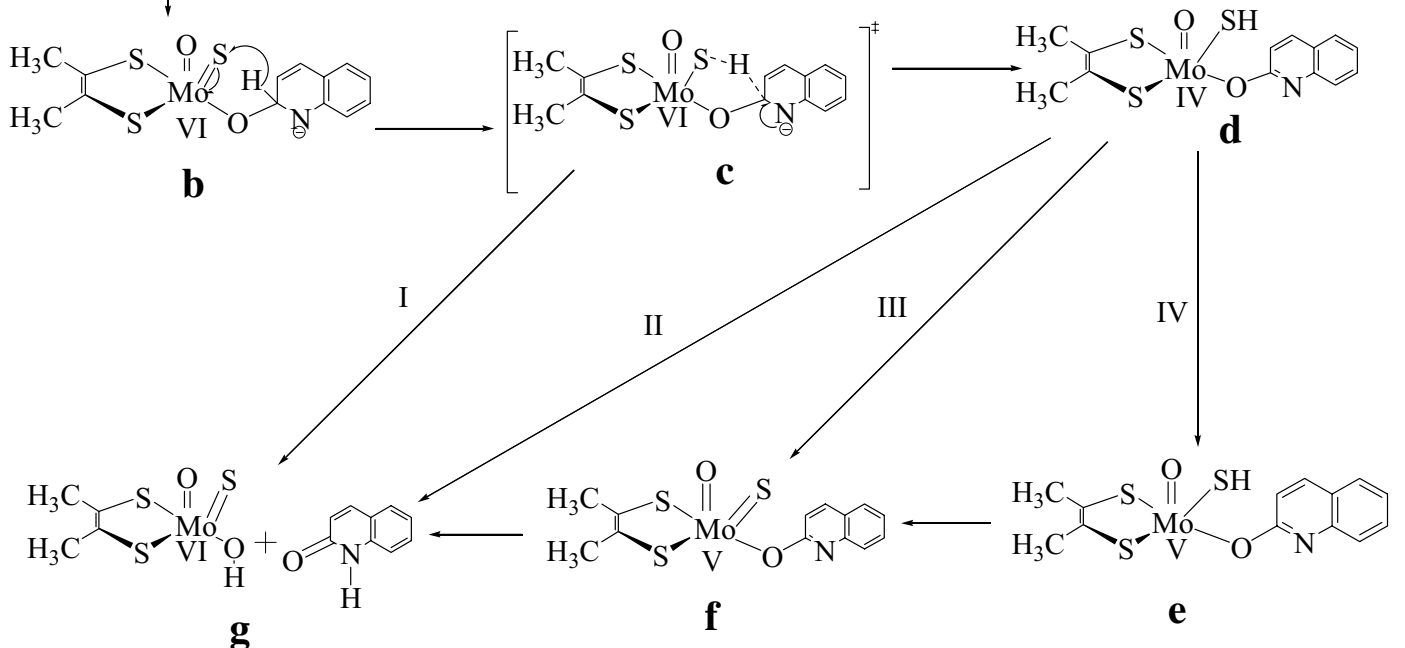

Scheme 2 The geometries that were optimized to probe a reaction mechanism for the catalytic oxidative hydroxylation of quinoline by Qor (developed from scheme 1) 


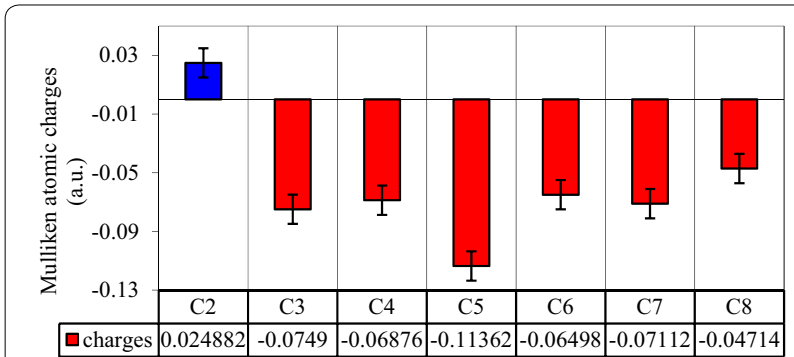

Fig. 3 A plot of Muliken atomic charges, on the carbon atoms, obtained from the optimized structure of unbound quinoline. The position of the carbon atoms are indicated on Fig. 2

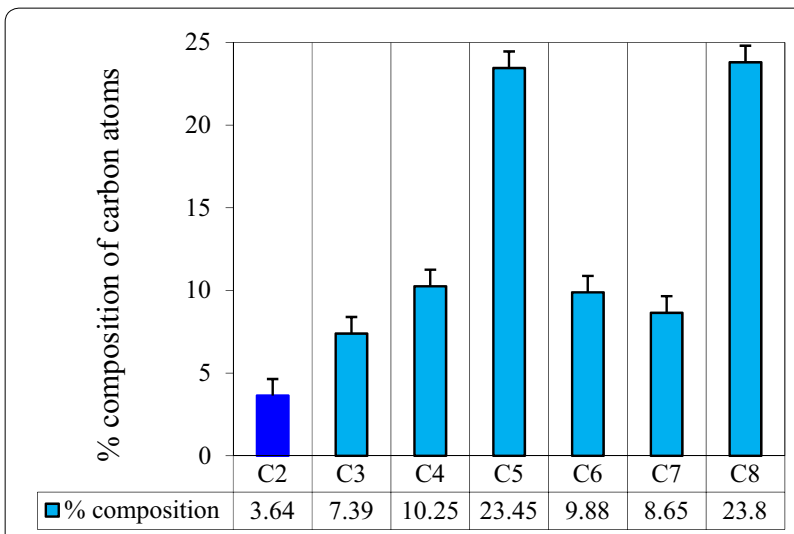

Fig. 4 The percentage contribution of the carbon atoms to HOMOs of quinoline obtained from AOMix calculation

Therefore, the data from Mulliken atomic charge profile, \% contribution on HOMO, and total energies are in favor of $\mathrm{C}_{2}$-pyridine as the preferred interaction site for quinoline. The result is consistent with the previous findings that quinoline becomes hydroxylated at $\mathrm{C}_{2}$ atom of the heterocyclic nitrogen containing ring [1].

\section{Prediction and characterization of transition state structure}

The total energies from the linear transit scan calculation for quinoline bound to the reductive half-reaction active site of Qor are plotted as a function of $\mathrm{S}_{\mathrm{Mo}}-\mathrm{H}_{\mathrm{RH}}$ distance (Fig. 5). The total energy profile was used to locate the initial guess for the transition state structure. As a result, the initial guess for the transition state structure was assigned for the geometry with highest energy at $\mathrm{S}_{\mathrm{Mo}^{-}}$ $\mathrm{H}_{\mathrm{RH}}$ distances $1.946 \AA$.

In addition to the total energies, the Mulliken atomic charges on selected elements $\left(\mathrm{C}_{\mathrm{RH}}, \mathrm{H}_{\mathrm{RH}}, \mathrm{O}_{\text {eq }}, \mathrm{Mo}, \mathrm{O}_{\text {oxo }}\right.$, $\mathrm{S}_{\mathrm{Mo}}, \mathrm{S}_{\alpha}$, and $\mathrm{S}_{\beta}$ ) from linear transit scan calculations were tabulated (Table 1).

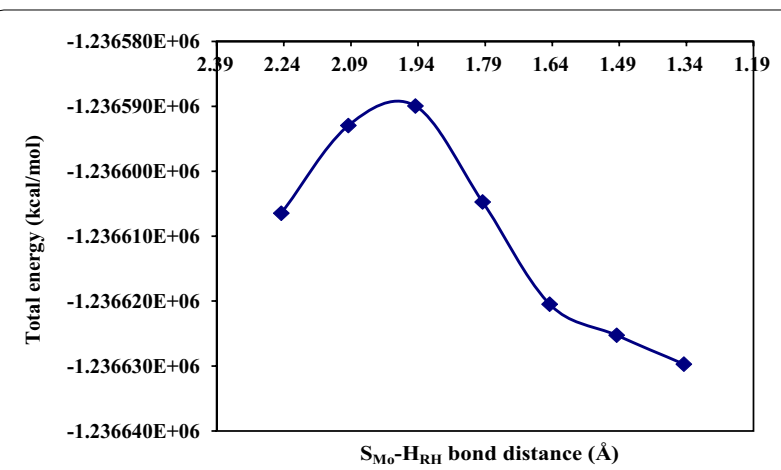

Fig. $\mathbf{5}$ The total energy plots used to locate the initial guess geometry for the transition state structure search

The Mulliken atomic charges on Mo are 0.616, 0.584, and 0.414 respectively, for the substrate bound intermediate, transition state, and product bound intermediate. This reflects a decrease in the partial positive charge on Mo ion as $\mathrm{H}_{\mathrm{RH}}$ migrates from $\mathrm{C}_{\mathrm{RH}}$ to $\mathrm{S}_{\mathrm{Mo}}$. The decrease in charge on Mo indicates the development of negatively charged particles on it. This is consistent with the reduction of Mo as the substrate bound active site $\left(\mathrm{Mo}^{(+\mathrm{VI})}\right)$ is converted to the product bound active site $\left(\mathrm{Mo}^{(+\mathrm{IV})}\right)$. Unlike Mo ion, the Mulliken atomic charge on substrate carbon $\left(\mathrm{C}_{\mathrm{RH}}\right)$ was shown to increase as $\mathrm{H}_{\mathrm{RH}}$ migrates from $\mathrm{C}_{\mathrm{RH}}$ to $\mathrm{S}_{\mathrm{Mo}}$. The charges on $\mathrm{C}_{\mathrm{RH}}$ are $0.084,0.198$, and 0.330 , respectively, at the substrate bound intermediate, transition state, and product bound intermediate. The profile reveals that the partial positive charges on $\mathrm{C}_{\mathrm{RH}}$ was shown to increase by a factor of two as $\mathrm{H}_{\mathrm{RH}}$ moves from the substrate bound carbon to the transition states and further increased by $66.3 \%$ as $\mathrm{H}_{\mathrm{RH}}$ moves to the product bound intermediate. The increase in partial positive charge on $\mathrm{C}_{\mathrm{RH}}$ is due to the partial transfer of electrons away from it. The increase and decrease in the partial negative charges on Mo and $\mathrm{C}_{\mathrm{RH}}$ is consistent with the assumption that $\mathrm{Mo}$ is reduced from $\left(\mathrm{Mo}^{(+\mathrm{VI})}\right)$ to $\left(\mathrm{Mo}^{(+\mathrm{IV})}\right)$ in the course of the reaction, due to the transfer of electrons from $\mathrm{C}_{\mathrm{RH}}$ the molybdenum center. Although the changes in magnitude are not comparable, the charge on the equatorial oxygen $\left(\mathrm{O}_{\text {eq }}\right)$ shows the same trend as $\mathrm{C}_{\mathrm{RH}}$. The atomic charge values on $\mathrm{O}_{\mathrm{eq}}$ are $-0.576,-0.544$, and -0.469 when $\mathrm{H}_{\mathrm{RH}}$ is at the substrate bound carbon, transition state, and product bound sulfido terminal, respectively. The decrease in the partial negatively charged particles on $\mathrm{O}_{\text {eq }}$ might be due to the increase in the attraction of bonding electrons $\left(\mathrm{O}_{\mathrm{eq}}{ }^{-}\right.$ $\mathrm{C}_{\mathrm{RH}}$ ) by $\mathrm{C}_{\mathrm{RH}}$. On the other hand, the electropositivity of the substrate hydrogen $\left(\mathrm{H}_{\mathrm{RH}}\right)$ decreases as it moves from the substrate bound carbon to the product bound 
Table 1 Mulliken atomic charges for selected elements from linear transit scan calculations

\begin{tabular}{|c|c|c|c|c|c|c|c|c|}
\hline $\begin{array}{l}\mathrm{S}_{\mathrm{Mo}_{0}}-\mathrm{H}_{\mathrm{RH}} \\
(\mathrm{A})\end{array}$ & $C_{R H}$ & $\mathrm{H}_{\mathrm{RH}}$ & $\mathrm{O}_{\mathrm{eq}}$ & Mo & $O_{\text {oxo }}$ & $\mathrm{S}_{\mathrm{Mo}}$ & $S_{a}$ & $S_{\beta}$ \\
\hline 1.346 & 0.330 & 0.011 & -0.469 & 0.414 & -0.545 & -0.391 & -0.240 & -0.221 \\
\hline 1.496 & 0.323 & -0.029 & -0.467 & 0.428 & -0.543 & -0.367 & -0.224 & -0.219 \\
\hline 1.646 & 0.328 & -0.053 & -0.469 & 0.428 & -0.542 & -0.359 & -0.220 & -0.215 \\
\hline 1.796 & 0.335 & -0.085 & -0.473 & 0.428 & -0.539 & -0.353 & -0.213 & -0.207 \\
\hline 1.946 & 0.199 & 0.048 & -0.544 & 0.584 & -0.532 & -0.444 & -0.184 & -0.180 \\
\hline 2.096 & 0.195 & 0.058 & -0.562 & 0.618 & -0.529 & -0.474 & -0.172 & -0.172 \\
\hline 2.246 & 0.084 & 0.142 & -0.576 & 0.616 & -0.567 & -0.626 & -0.220 & -0.181 \\
\hline
\end{tabular}

sulfido terminal. This indicates that the accumulation of negatively charged particles, on $\mathrm{H}_{\mathrm{RH}}$, is high when it is found at the sulfido terminal compared to the substrate bound. Unlike all the other inorganic ligands coordinated to Mo, the atomic charge distribution on the apical oxygen shows no more significant variation as $\mathrm{H}_{\mathrm{RH}}$ moves from $C_{\mathrm{RH}}$ to $\mathrm{S}_{\mathrm{Mo}}$. As a result, it can be reasonably concluded that the apical oxo plays a "spectator" role in the reaction. In previous works, it was reported that the apical oxo may play an important role in the stabilization of the intermediate states of the catalytic cycle by increasing the $\mathrm{Mo}=\mathrm{O}$ strength by "spectator oxo effect" though it is not directly participated in catalysis [1]. The charge distribution on $\mathrm{H}_{\mathrm{RH}}$ at $\mathrm{C}_{\mathrm{RH}}-\mathrm{H}_{\mathrm{RH}}$, TS, and $\mathrm{S}_{\mathrm{Mo}}-\mathrm{H}_{\mathrm{RH}}$ are $0.142,0.048$, and 0.041 , respectively. This result shows that the electropositivity of $\mathrm{H}_{\mathrm{RH}}$ is decreased by $66.3 \%$ as $\mathrm{H}_{\mathrm{RH}}$ move from $\mathrm{C}_{\mathrm{RH}}$ to the transition state and further decreased by $76.1 \%$ at $\mathrm{S}_{\mathrm{Mo}}$ compared to the transition state. The rapid decrease in electropositivity or rapid increase in electronegativity of $\mathrm{H}_{\mathrm{RH}}$, as it migrates from $\mathrm{C}_{\mathrm{RH}}$ to $\mathrm{S}_{\mathrm{Mo}}$, is due to the development of partial positive charges on $\mathrm{H}_{\mathrm{RH}}$. This result supported hydride transfer from $\mathrm{C}_{\mathrm{RH}}$ to $\mathrm{S}_{\mathrm{Mo}}$ which is consistent with recent investigations [20]. The partial negative charge distributions on the sulfido terminal $\left(\mathrm{S}_{\mathrm{Mo}}\right)$ are $-0.626,-0.444$, and -0.391 as $\mathrm{H}_{\mathrm{RH}}$ is found at $\mathrm{C}_{\mathrm{RH}}$, transition state, and $\mathrm{S}_{\mathrm{Mo}}$ in the respective order. This result shows the increase in the electropositivity of $\mathrm{S}_{\mathrm{Mo}}$ as $\mathrm{H}_{\mathrm{RH}}$ moves from $\mathrm{C}_{\mathrm{RH}}$ to $S_{\text {Mo }}$ itself. This might be due to the transfer of partial negatively charged electrons from the $\pi$-type electrons between apical oxygen and molybdenum $(\mathrm{Mo}=\mathrm{O})$ to the empty $d_{x y}$ orbitals of Mo. Finally, the atomic charge distributions on the dithiolene sulfurs slightly increase as $\mathrm{H}_{\mathrm{RH}}$ moves from $\mathrm{C}_{\mathrm{RH}}$ to $\mathrm{S}_{\mathrm{Mo}}$. The result shows that the partial negatively charged particles are increased by 0.019 and 0.040 for $S_{\alpha}$ and $S_{\beta}$, respectively. The increase in electronegativity might be due to the back donation of electrons from the $d_{x y}$ orbital's of Mo to the $p_{z}$ orbitals of the dithiolene sulfur atoms. It implies that electrons from the Mo center passes to the other redox centers through the dithiolene sulfurs. The change in electronegativity of $S_{\beta}$ is higher than $S_{\alpha}$ by $0.021 . S_{\beta}$ is at about $150.134^{\circ}$ angle from the equatorial oxygen which implies that $S_{\beta}$ is almost trance to the equatorial oxygen. For this reason, $S_{\beta}$, which carried the partial negatively charged particles, would have a trance effect on the equatorial oxygen which is a leaving group in the course of the reaction.

Various bond lengths which are expected to be formed and broken while $\mathrm{H}_{\mathrm{RH}}$ linearly moves from $\mathrm{C}_{\mathrm{RH}}$ to $\mathrm{S}_{\mathrm{Mo}}$ were collected from the out puts of the optimized structures. The optimized bond lengths versus the $\mathrm{S}_{\mathrm{Mo}}-\mathrm{H}_{\mathrm{RH}}$ bond distances were plotted (Fig. 6). The increase in the bond length of $\mathrm{Mo}-\mathrm{O}_{\text {eq }}$ (Fig. 6) shows that the $\mathrm{Mo}-\mathrm{O}_{\text {eq }}$ bond is broken as $\mathrm{H}_{\mathrm{RH}}$ moves from $\mathrm{C}_{\mathrm{RH}}$ to $\mathrm{S}_{\mathrm{Mo}}$. On the contrary, the $\mathrm{C}_{\mathrm{RH}}-\mathrm{O}_{\mathrm{eq}}$ bond length is decreased as $\mathrm{H}_{\mathrm{RH}}$ migrates from $\mathrm{C}_{\mathrm{RH}}$ to $\mathrm{S}_{\mathrm{Mo}}$. The shortening of $\mathrm{C}_{\mathrm{RH}}-\mathrm{O}_{\text {eq }}$ bond length leads to the accumulation of electron density on the substrate carbon $\left(\mathrm{C}_{\mathrm{RH}}\right)$. The $\mathrm{C}_{\mathrm{RH}}-\mathrm{O}_{\text {eq }}$ bond length is longer than Mo- $\mathrm{O}_{\text {eq }}$ bond length at $\mathrm{C}_{\mathrm{RH}}-\mathrm{H}_{\mathrm{RH}}$. However, the $\mathrm{C}_{\mathrm{RH}}-\mathrm{O}_{\text {eq }}$ bond length is shorter than the $\mathrm{Mo}-\mathrm{O}_{\mathrm{eq}}$ bond length at the transition state. This result indicates that the $\mathrm{C}_{\mathrm{RH}}-\mathrm{O}_{\text {eq }}$ bond is formed and the Mo- $\mathrm{O}_{\text {eq }}$ bond is broken before the transition state. The $\mathrm{C}_{\mathrm{RH}}-\mathrm{H}_{\mathrm{RH}}$ bond

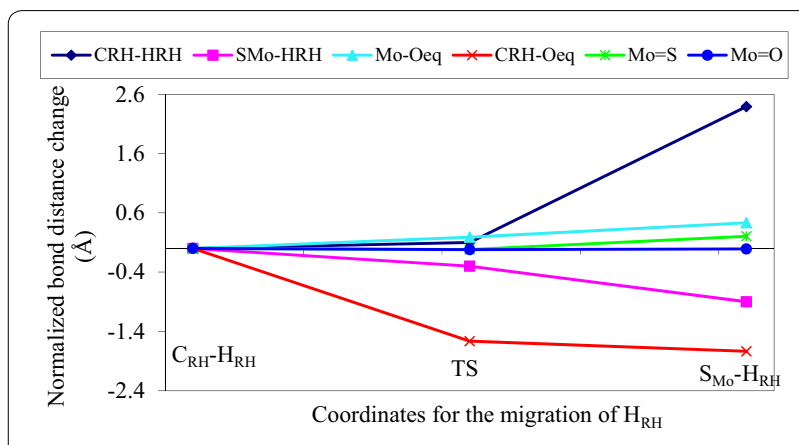

Fig. 6 A plot for the normalized bond distance differences as a function of coordinates $\left(\mathrm{C}_{\mathrm{RH}}-\mathrm{H}_{\mathrm{RH}}, \mathrm{TS}, \mathrm{H}_{\mathrm{RH}}\right)$ obtained from the linear transit calculation of quinoline bound with the reductive half reaction active site of Qor 
length is elongated unlike the $\mathrm{S}_{\mathrm{Mo}}-\mathrm{H}_{\mathrm{RH}}$ bond length which is decreased as $\mathrm{H}_{\mathrm{RH}}$ moves from $\mathrm{C}_{\mathrm{RH}}$ to $\mathrm{S}_{\mathrm{Mo}}$. At the transition state, the $\mathrm{C}_{\mathrm{RH}}-\mathrm{H}_{\mathrm{RH}}$ bond length is lower than the $\mathrm{S}_{\mathrm{Mo}}-\mathrm{H}_{\mathrm{RH}}$ bond length. This shows that the transition state is more substrate like. Therefore, according to the Hammond's principle, the transition state is early transition state. The $\mathrm{Mo}=\mathrm{S}$ bond length is increased as $\mathrm{H}_{\mathrm{RH}}$ moves from $\mathrm{C}_{\mathrm{RH}}$ to $\mathrm{S}_{\mathrm{Mo}}$. The increase in the $\mathrm{Mo}=\mathrm{S}$ bond length shows the loss of the double bond character. This might be due to the delocalization of electrons between $\mathrm{Mo}$ and $\mathrm{S}_{\mathrm{Mo}}$. Almost all the bond lengths of the atoms that are directly coordinated to the molybdenum metal center shows a significant change except $\mathrm{Mo}=\mathrm{O}_{\text {oxo }}$ bond length which is almost constant whilst $\mathrm{H}_{\mathrm{RH}}$ moves from $\mathrm{C}_{\mathrm{RH}}$ to $\mathrm{S}_{\mathrm{Mo}}$. This shows that the apical oxo plays a spectator role throughout the reaction and it is consistent with the results obtained from the atomic charges as described above.

In summary, results obtained from the bond lengths possibly predicts that the events which are proposed to takes place at the transition state such as bond formation $\left(\mathrm{C}_{\mathrm{RH}}-\mathrm{O}_{\mathrm{eq}}\right.$ and $\left.\mathrm{S}_{\mathrm{Mo}}-\mathrm{H}_{\mathrm{RH}}\right)$ and bond cleavage $\left(\mathrm{Mo}-\mathrm{O}_{\mathrm{eq}}\right.$ and $\mathrm{C}_{\mathrm{RH}}-\mathrm{H}_{\mathrm{RH}}$ ) inherit the characteristics of the substrate bound. Moreover, the lengthening of bond lengths predicts the cleavage of $\mathrm{Mo}-\mathrm{O}_{\mathrm{eq}}$ and $\mathrm{C}_{\mathrm{RH}}-\mathrm{H}_{\mathrm{RH}}$ bonds while the shortening of bond lengths predicts the formation of $\mathrm{C}_{\mathrm{RH}}-\mathrm{O}_{\mathrm{eq}}$ and $\mathrm{C}_{\mathrm{RH}}-\mathrm{H}_{\mathrm{RH}}$ bonds during the oxidative hydroxylation of quinoline in the reductive half-reaction active site of Qor.

The percentage contribution of the molecular orbital fragments $\left(\mathrm{Mo}_{\mathrm{dxy}}\right)$ to the highest occupied molecular orbitals (HOMOs) of Qor at the substrate bound $\mathrm{C}_{\mathrm{RH}^{-}}$ $\mathrm{H}_{\mathrm{RH}}$, transition state, and $\mathrm{S}_{\mathrm{Mo}}-\mathrm{H}_{\mathrm{RH}}$ are 2.17, 21.67 and 80.57 , respectively. The result shows that the metallic character increase as $\mathrm{H}_{\mathrm{RH}}$ moves from $\mathrm{C}_{2}$ of quinoline to $\mathrm{S}_{\mathrm{Mo}}$. The increase in metallic character depicts that electrons are transferred from $\mathrm{C}_{2}$ of quinoline to the Mo center and hence the reduction of $\mathrm{Mo}^{(+\mathrm{VI})}$ to $\mathrm{Mo}^{(+\mathrm{IV})}$ during the oxidative hydroxylation of quinoline by Qor.

\section{Probing a reaction mechanism for the oxidation of quinoline}

After the transition state structure was located, various geometries (Scheme 2) were optimized in order to understand the events which take place during the catalytic conversion of quinoline to 1-hydro-2-oxoquinoline and probe a plausible mechanistic route for the oxidative hydroxylation of quinoline in the reductive half-reaction active site of Qor. In this reaction mechanism the equatorial oxygen is proposed to nucleophilically attack the electron deficient carbon $\left(C_{2}\right)$ to form structure (b) after the deprotonation of the equatorial hydroxyl group of the active site by Glu713. The possible inorganic ligands that might be considered for the nucleophilic attack on $\mathrm{C}_{2}$ of quinoline are the equatorial oxo $\left(\mathrm{O}_{\text {eq }}\right)$, apical oxo $\left(\mathrm{O}_{\text {oxo }}\right)$ and sulfido terminal $\left(\mathrm{S}_{\mathrm{Mo}}\right)$.

The Mulliken atomic charge distributions on $\mathrm{O}_{\text {eq }}, \mathrm{O}_{\text {oxo }}$, and $\mathrm{S}_{\mathrm{Mo}}$ of the active site before nucleophilic attack [at structure (a)] are $-0.597,-0.468$, and -0.415 (Table 2). This result shows that the accumulations of negatively charged particles on $\mathrm{O}_{\mathrm{eq}}$ are higher than $\mathrm{O}_{\text {oxo }}$ and $\mathrm{S}_{\mathrm{Mo}}$. It assures that $\mathrm{O}_{\text {eq }}$ is preferred for nucleophilic attack on $\mathrm{C}_{2}$ of quinoline. This is consistent with recent experimental results that the catalytically labile site should be $\mathrm{O}_{\text {eq }}$ coordinated with Mo rather than $\mathrm{O}_{\text {oxo }}$ [19]. On the other hand, the atomic charge on $\mathrm{C}_{2}$ of quinoline is 0.025 which shows that $\mathrm{C}_{2}$ and $\mathrm{O}_{\text {eq }}$ are oppositely charged as a result, electrostatic force of attraction would be experienced between $\mathrm{O}_{\text {eq }}$ and $\mathrm{C}_{2}$. Hence, $\mathrm{O}_{\text {eq }}$ can be nucleophilically attack $\mathrm{C}_{2}$ which is electron deficient and the reaction mechanism proceeds through nucleophilic attack on $\mathrm{C}_{2}$ of quinoline. In line with finding, X-ray structural analysis showed the lack of enough space for the substrate to approach the Mo center from the axial direction and hence $\mathrm{O}_{\text {eq }}$ is more reactive than $\mathrm{O}_{\text {oxo }}$ in the nucleophilic attack [20]. Hence, from this result it is reasonably concluded that $\mathrm{O}_{\mathrm{eq}}$ is preferred for nucleophilic attacks on $\mathrm{C}_{2}$ of quinoline.

Table 2 The Mulliken atomic charges for selected elements from geometry optimization for the structures shown in Scheme 2

\begin{tabular}{|c|c|c|c|c|c|c|c|c|}
\hline Geometries & $\mathrm{C}_{\mathrm{RH}}$ & $\mathrm{H}_{\mathrm{RH}}$ & $\mathrm{O}_{\text {eq }}$ & Mo & $\mathrm{O}_{\text {oxo }}$ & $\mathrm{S}_{\mathrm{Mo}}$ & $S_{a}$ & $S_{\beta}$ \\
\hline$a$ & 0.020 & 0.117 & -0.597 & 0.662 & -0.468 & -0.415 & -0.153 & -0.054 \\
\hline b & 0.110 & 0.128 & -0.586 & 0.633 & -0.547 & -0.644 & -0.231 & -0.182 \\
\hline c & 0.200 & 0.049 & -0.541 & 0.579 & -0.520 & -0.448 & -0.187 & -0.175 \\
\hline$d$ & 0.329 & -0.006 & -0.467 & 0.410 & -0.524 & -0.383 & -0.238 & -0.216 \\
\hline e & 0.342 & 0.035 & -0.526 & 0.528 & -0.466 & -0.235 & -0.113 & -0.079 \\
\hline$f$ & 0.349 & - & -0.479 & 0.473 & -0.522 & -0.584 & -0.205 & -0.168 \\
\hline
\end{tabular}


After the nucleophilic attack, it is proposed that the Mo- $-\mathrm{O}_{\text {eq }}$ and $\mathrm{C}_{\mathrm{RH}}-\mathrm{H}_{\mathrm{RH}}$ bonds are broken while $\mathrm{C}_{\mathrm{RH}}-\mathrm{O}_{\mathrm{eq}}$ and $\mathrm{S}_{\mathrm{Mo}}-\mathrm{H}_{\mathrm{RH}}$ are formed in the oxidative hydroxylation reaction mechanism as clearly described above. The formation and cleavage of these bonds are further proved by the results obtained from the bond order profiles (Fig. 7). The bond orders of $\mathrm{Mo}-\mathrm{O}_{\text {eq }}$ and $\mathrm{C}_{\mathrm{RH}}-\mathrm{H}_{\mathrm{RH}}$ are decreased unlike $\mathrm{C}_{\mathrm{RH}}-\mathrm{O}_{\text {eq }}$ and $\mathrm{S}_{\mathrm{Mo}}-\mathrm{H}_{\mathrm{RH}}$ as structure (b) is converted to structure (d) (Fig. 7). The decrease in the bonders of $\mathrm{Mo}-\mathrm{O}_{\mathrm{eq}}$ and $\mathrm{C}_{\mathrm{RH}}-\mathrm{H}_{\mathrm{RH}}$ assures the cleavage of these bonds in the reaction. On the other hand, the increase in the bond orders of $\mathrm{C}_{\mathrm{RH}}-\mathrm{O}_{\text {eq }}$ and $\mathrm{S}_{\mathrm{Mo}}-\mathrm{H}_{\mathrm{RH}}$ predicts the formation of these bonds as structure (b) is converted to structure (d).

It is already described that the reaction mechanism can be proceed through nucleophilic attack by the equatorial oxygen on $\mathrm{C}_{2}$ and hydride transfer is taking place during the oxidative hydroxylation of quinoline. But, further description is requited whether the reaction mechanism is concerted or stepwise process.

The normalized total energy differences between structure (b) $\left(\mathrm{Mo}^{(+\mathrm{VI})}-\mathrm{O}_{\mathrm{eq}}-\mathrm{C}_{\mathrm{RH}}\right)$, which is formed as a result of nucleophilic attack on the substrate carbon, and the transition state [structure (c), $\left(\mathrm{C}_{\mathrm{RH}} \ldots \mathrm{H}_{\mathrm{RH}} \ldots \mathrm{S}_{\mathrm{Mo}}\right)^{\ddagger}$ ] is $10.86 \mathrm{kcal} / \mathrm{mol}$. This large energy difference indicates the difficulty of the conversion of structures (b) to (c) which argued the step wise process of nucleophilic attack. However, it is not sufficient evidence to conclude that the reaction mechanism is concerted. Therefore, it is better to compare the energy of structure (b) with the energy of the resting state geometry [structure (a)]. The normalized total energy difference between structure (a) and (b) is $414.41 \mathrm{kcal} / \mathrm{mol}$ (Fig. 8). This large energy barrier lets the existence of structure (b) under question unless there is a high energy species or intermediate between structures (a) and (b). Therefore, there might be a transition state structure (TS1) between structures (a) and (b) as shown in Fig. 9. For this reason, it is supposed that the

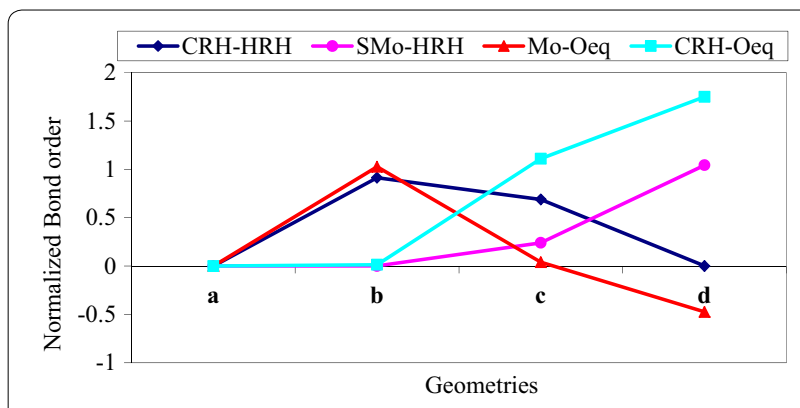

Fig. 7 A plot of the normalized bond order for the active site structure bound to quinoline as a function of the respected geometries

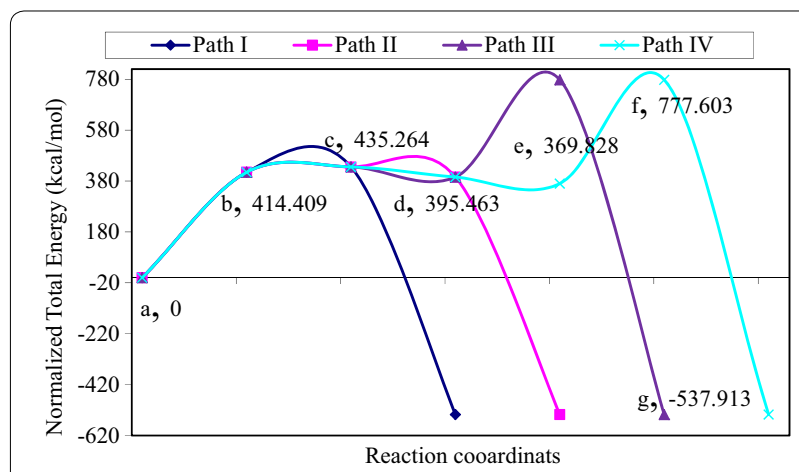

Fig. 8 The total normalized energy of the four possible routes for the oxidation of quinoline in the active site of Qor

abstraction of proton from the equatorial hydroxyl group of the active site by the amino acid residue (Glu743) and the nucleophilic attack of the equatorial oxygen on the substrate carbon are occurred simultaneously and coexist as transition state (TS1) between the resting state geometry [structure (a)] and the substrate bound intermediate [structure (b)]. In this case, the reaction would have two transition states designated as TS1 and TS-c (Fig. 9). The existence or inexistence of TS1 could be evaluated in comparison with TS-c.

The Mulliken atomic charges distribution on $\mathrm{O}_{\mathrm{eq}}$ are $-0.597,-0.586$, and -0.467 at the structures (a), (b), and (d), respectively (Table 2). This indicates that the charge difference between structures (a) and (b) is 0.012 and for that of structures (b) and (d) is 0.119. The change in atomic charges on $\mathrm{O}_{e q}$ while structure (a) is converted to structure (b) is insignificant compared to the large charge difference observed when structure (b) is converted to structure (d). This large atomic charge differences between structures (b) and (d) is due to the presence of TS-c (hydride shift). Similarly, a comparable charge difference is expected if TS1 is found between structures (a) and (b). However, the result shows that there is no significant charge difference between structures (a) and (b). In addition to that, the atomic charge distribution on substrate carbon $\left(C_{2}\right)$ is also incomparable while structure (a) is converted to structure (b) and structure (b) is converted to structure (d). Once again, the charge difference between structures (a) and (b) (0.091) is insignificant compared to the charge difference between structures (b) and (d) (0.218). From this result, it can be concluded that the significance charge difference between structure (b) and (d) might be due to the presence of the transition state (TS-c). On the other hand, there is no significant charge difference between structures (a) and (b) which might be due to the inexistence of transition state (TS1). Therefore, transition state one (TS1) proposed for the 


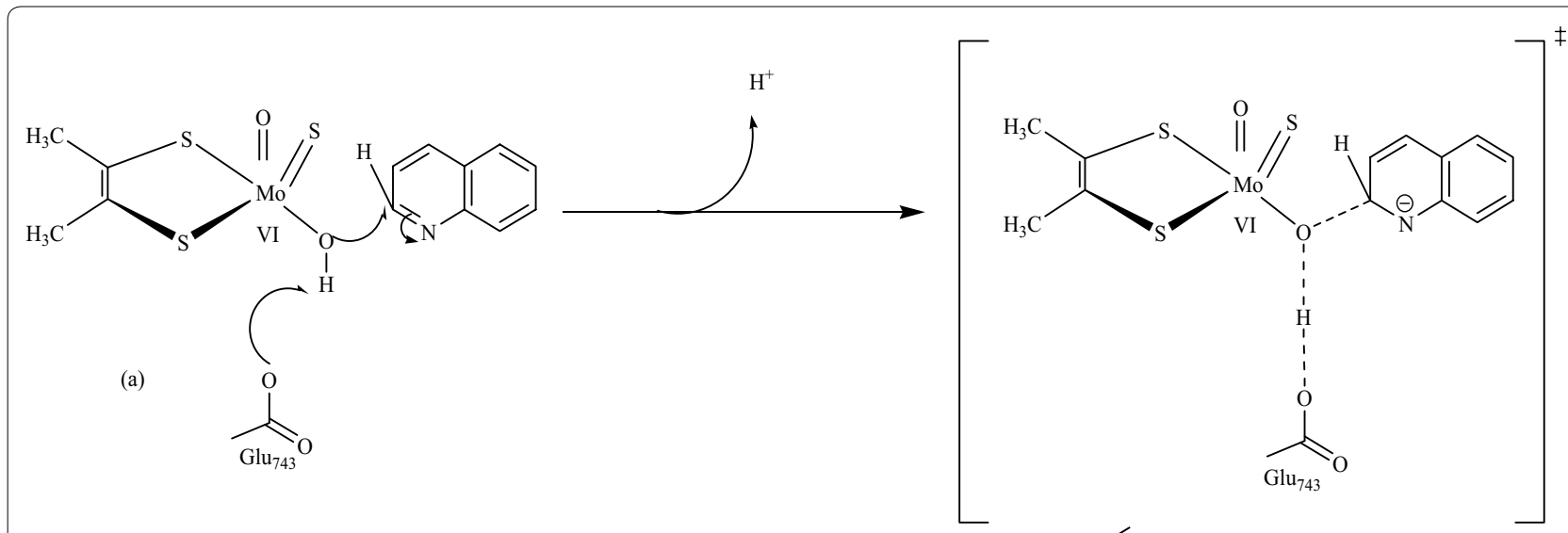

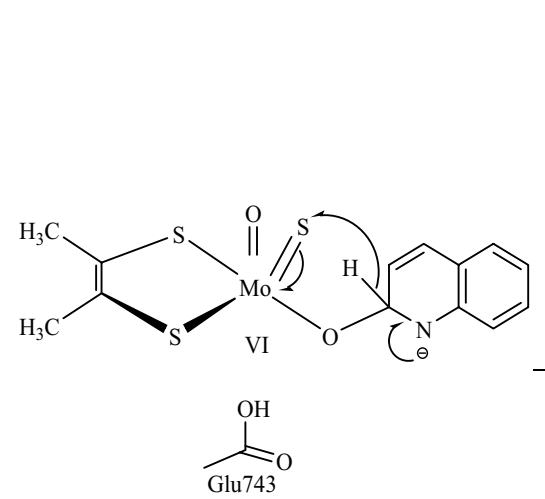

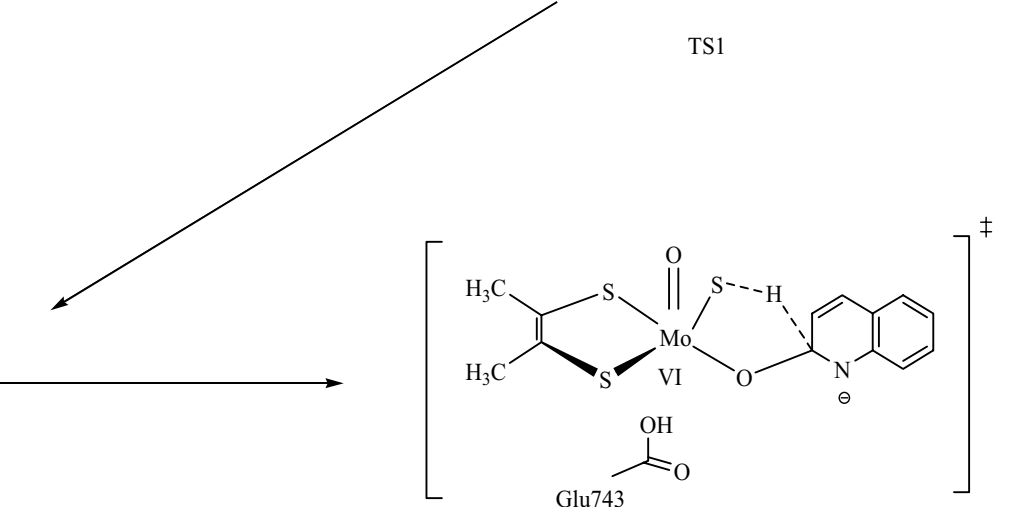

TS-c

(b)

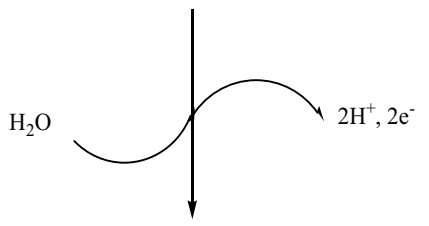<smiles>CC(Sc1ccc2ccccc2n1)C(=O)O</smiles><smiles>CC(=O)O</smiles>

Fig. 9 The proposed reaction mechanism to probe the feasibility of stepwise or concerted process for the oxidative hydroxylation reaction of quinoline in the active site of Qor

reaction mechanism (Fig. 9) is not existed and the energy barrier between structures (b) and (c) is large (Fig. 10) which makes the conversion of structure (b) to structure (c) difficult. Hence, there is no intermediate [structure (b)] in the reaction mechanism.

In addition to that, there is no significant change in the percentage contribution of $\mathrm{Mo}_{\mathrm{dxy}}$ to the HOMO as structure $(\mathrm{a}, 2.96)$ is converted to $(\mathrm{b}, 2.11)$. On the contrary, the conversion of structures (a) to (c, 20.96) or (c) to (d, 80.54 ) is takes placed with dramatic increase in the percentage contribution of $\mathrm{Mo}_{\mathrm{dxy}}$ to the $\mathrm{HOMO}$ which assures the inexistence of structure (b) in the reaction mechanism. Similarly, the HOMOs in Fig. 10 show that there is no significant change in the electron densities distribution between structures (a) and (b). If structure (b) is existed in the reaction mechanism, there should 
be a change in the electrons densities distribution from structures (a) to (b) as the change shown from structures (a) to (c) and structures (c) to (d) in Fig. 10.

Once again, this result predicts that structure (b) is not existed in the reaction mechanism. Consequently the nucleophilic attack on the substrate carbon by the equatorial oxygen and the hydride transfer from the substrate carbon to the sulfido terminal of the active site are proposed to be concerted for the oxidative hydroxylation reaction mechanism of quinoline in the active site of Qor. This finding is consistent with theoretical and isotopic experimental results that a concerted (one step) mechanism by the deprotonated active site is the most plausible for reactions catalyzed by molybdenum hydroxylases [20].

Moreover, $\mathrm{C}_{\mathrm{RH}}-\mathrm{O}_{\mathrm{eq}}$ and $\mathrm{C}_{\mathrm{RH}}-\mathrm{H}_{\mathrm{RH}}$ bond lengths are changed from 1.452 to 3.137 and 1.201 to 1.091 , respectively as $\mathrm{H}_{R H}$ migrates from the substrate bound [structure (b)] to the transition state (TS-c). This result indicates that the formation of $\mathrm{C}_{\mathrm{RH}}-\mathrm{O}_{\text {eq }}$ bond is much higher (about 15 times) than the cleavage of $\mathrm{C}_{\mathrm{RH}}-\mathrm{H}_{\mathrm{RH}}$ bond. It implies that nucleophilic attack $\left(\mathrm{C}_{\mathrm{RH}}-\mathrm{O}_{\text {eq }}\right)$ is faster than hydride transfer $\left(\mathrm{C}_{\mathrm{RH}}-\mathrm{H}_{\mathrm{RH}}\right)$. Hence, hydride transfer is the rate limiting step in the catalysis stage of the oxidative hydroxylation of quinoline in the reductive half-reaction active site of Qor. This result is consistent with previous findings that hydride transfer is the rate determining step in the concerted reaction mechanism unlike the stepwise mechanism in which the nucleophilic attack is the rate determining step [19].

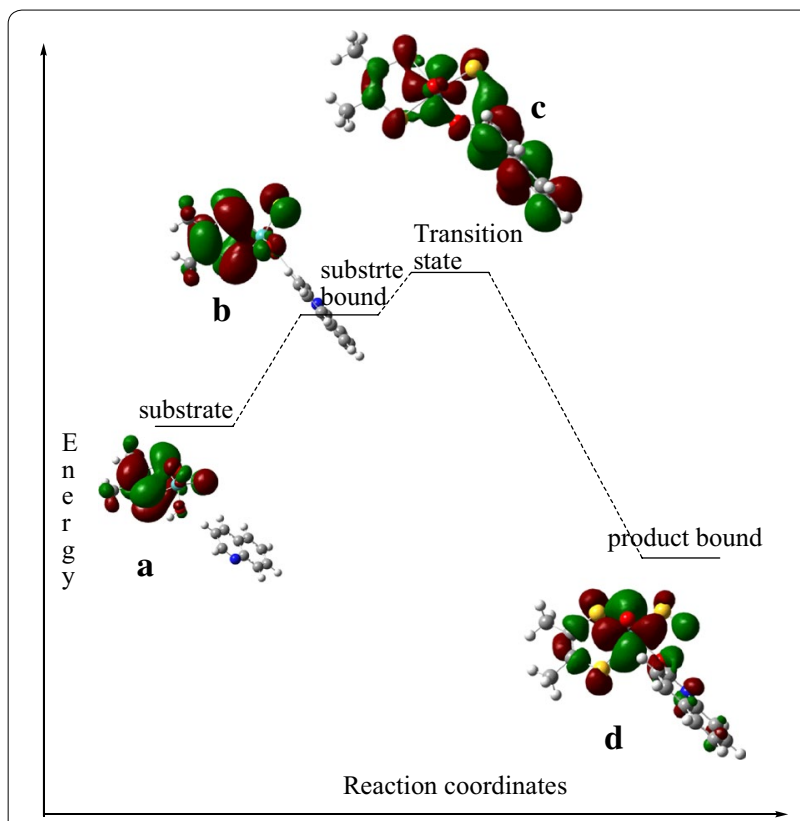

Fig. 10 A plot of the energy of HOMOs as a function of the reaction coordinates for the oxidation of quinoline to 1-hydro-2-oxoquinoloine
After the product bound [structure (d)] is formed, it is further dissociated into various structures either through one or two electron transfer process to give the most stable product [structure (g)]. There are four possible paths (I, II, III and IV) for the dissociation of structure (d) into structure g (Fig. 9). Path (III) [(a), (c), (d), (f), and (g)] and path (IV) [(a), (c), (d), (e), (f), and (g)] are passed through the complex (f) which has $65.436 \mathrm{kcal} / \mathrm{mol}$ energy barrier from the transition state. Hence, path (III) and (IV) can be ruled out due to the highest energy barrier relative to path (I) and (II). Path (II) [(a), (c), (d) and (g)] has $39.801 \mathrm{kcal} / \mathrm{mol}$ energy barrier between the transition state [structure (c)] and the product bound [structure (d)]. On the other hand Path (I) [(a), (c), and (g)] is passed through the transition state and directly converted to the product (structure g). Due to this higher energy barrier $(39.801 \mathrm{kcal} / \mathrm{mol})$ relative to path (I), the reaction is not expected to pass through path (II). Therefore, the formation of the product [structure (g)] through path (II), (III), and (IV) will be retarded by 39.801 , 65.436 , and $65.436 \mathrm{kcal} / \mathrm{mol}$ respectively relative to path (I). In path (I), the product is formed with minimum energy relative to the other paths. Hence, path (I) is preferred for the product release stage for the oxidative hydroxylation of quinoline in the reductive half-reaction active site of Qor.

In summary, the results obtained from energy, charges, bond length, and percentage contribution of the chemical fragments to the HOMOs, and molecular orbital analysis supported concerted reaction mechanism for the oxidation of quinoline to 1-hydro-2-oxoquinoline on the in the reductive half-reaction active site of Qor.

\section{Conclusion}

Density functional theory methods of electronic structures calculation was used for the study. Based on the data obtained from Mulliken atomic charge profile, \% contribution on $\mathrm{HOMO}$, and total energies, it is theoretically probed that $\mathrm{C}_{2}$ is the interaction site of quinoline.

The $\mathrm{S}_{\mathrm{Mo}}-\mathrm{H}_{\mathrm{RH}}$ bond distance for the model transition state structures of quinoline is found to be $1.960 \AA$. The transition state structure was confirmed with one imaginary negative frequency of -104.5 . The transition state total energy of quinoline is found to be $-1.2365899 \mathrm{E}+06 \mathrm{kcal} / \mathrm{mol}$.

The increase and the decrease in the partial positive charges on Mo and $\mathrm{C}_{2}$ of quinoline shows that molybdenum is reduced from $\mathrm{Mo}^{(+\mathrm{VI})}$ to $\mathrm{Mo}^{(+\mathrm{IV})}$ in the course of the reaction due to the transfer of electrons from $C_{2}$ of quinoline to the molybdenum center. Likewise, the partial negative charge on $\mathrm{O}_{\mathrm{eq}}$ is decreased due to the withdrawal of bonding electrons $\left(\mathrm{O}_{\mathrm{eq}}-\mathrm{C}_{\mathrm{RH}}\right)$ away from it. On the other hand, the electropositivity of the substrate hydrogen $\left(\mathrm{H}_{\mathrm{RH}}\right)$ is decreased due to the accumulation of negatively charged particles on it. The apical oxo plays a 
"spectator" role in the reaction as it shows insignificant charge variations. Moreover, the equatorial oxygen is a better nucleophile relative to the apical oxo since the accumulation of partial negative charge on the equatorial oxygen is higher than the apical oxo.

The increase and the decrease in the bond lengths predicted the cleavage of $\mathrm{Mo}-\mathrm{O}_{\text {eq }}$ and $\mathrm{C}_{\mathrm{RH}}-\mathrm{H}_{\mathrm{RH}}$ and formation of $\mathrm{C}_{\mathrm{RH}}-\mathrm{O}_{\mathrm{eq}}$ and $\mathrm{S}_{\mathrm{Mo}}-\mathrm{H}_{\mathrm{RH}}$ bonds at the transition state, respectively. The increase in metallic character of molybdenum revealed that electrons are transferred from $\mathrm{C}_{2}$ of quinoline to Mo center and hence the reduction of $\mathrm{Mo}^{(+\mathrm{VI})}$ to $\mathrm{Mo}^{(+\mathrm{IV})}$ during the oxidative hydroxylation of quinoline by Qor.

From the Mulliken atomic charge changes, it is reasonably predicted that the equatorial oxygen is a better nucleophile in the oxidative hydroxylation of quinoline. The decrease and the increase in the partially negatively charged particles on Mo and $\mathrm{C}_{2}$, respectively assured the transfer of electrons from $\mathrm{C}_{2}$ of quinoline to the Mo center. The accumulation of partial negative charges on the hydrogen atom at the product bound relative to the substrate bound, possibly predicted that hydrogen is transferred in the form of hydride $\left(\mathrm{H}+2 \mathrm{e}^{-}\right)$from $\mathrm{C}_{2}$ to $\mathrm{S}_{\mathrm{Mo}}$. Eventually, it is reasonably concluded that the oxidative hydroxylation of quinoline in the reductive half-reaction active site of Qor are concerted.

\section{Authors' contributions}

EAB carried out all the computional calculations, analyzed and interpreted the data. The author prepared, read and approved the final manuscript.

\section{Competing interests}

The author declares that he has no competing interests.

\section{Appendix}

See Fig. 11.

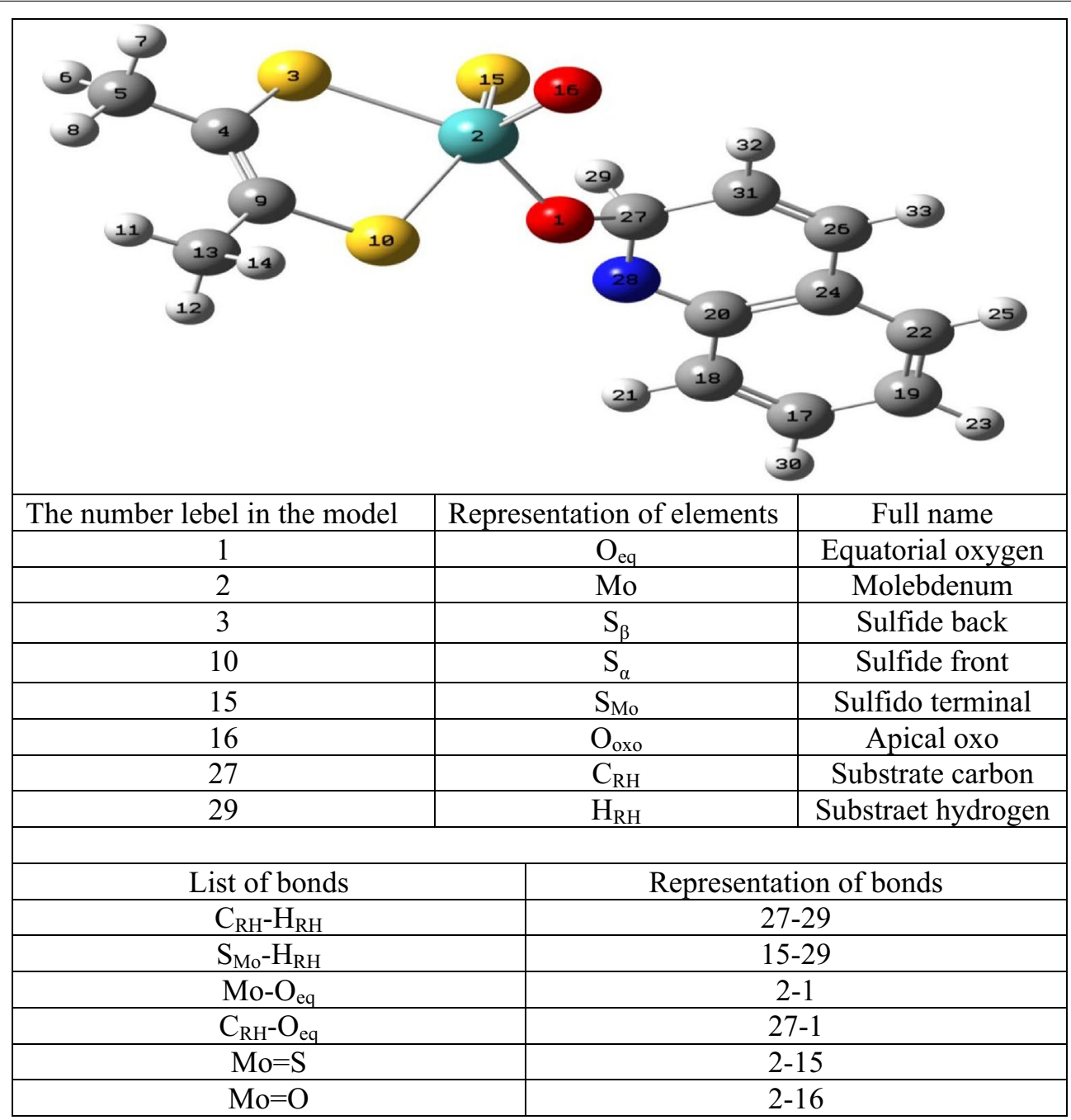

Fig. 11 The descriptions for the abbreviations: $\mathrm{C}_{\mathrm{RH}}, \mathrm{H}_{\mathrm{RH}}, \mathrm{O}_{\mathrm{eq}}, \mathrm{Mo}, \mathrm{O}_{\mathrm{oxo}}, \mathrm{S}_{\mathrm{Mo}^{\prime}} \mathrm{S}_{\alpha^{\prime}} \mathrm{S}_{\beta^{\prime}} \mathrm{C}_{\mathrm{RH}}-\mathrm{H}_{\mathrm{RH}}, \mathrm{C}_{\mathrm{RH}}-\mathrm{O}_{\text {eq, }} \mathrm{S}_{\mathrm{Mo}}-\mathrm{H}_{\mathrm{RH}}, \mathrm{Mo}-\mathrm{O}_{\mathrm{eq}}, \mathrm{S}_{\mathrm{Mo}}-\mathrm{H}_{\mathrm{RH}}, \mathrm{Mo}-\mathrm{S}$, and M=O 
Received: 20 May 2016 Accepted: 10 November 2016

Published online: 24 November 2016

\section{References}

1. Bonin I, Martins BM, Purvanov V, Fetzner S, Huber R, Dobbek H (2004) Active site geometry and substrate recognition of the molybdenum hydroxylase quinoline 2-oxidoreductase. Structure (London) 12:1425-1435

2. Schach S, Tshisuaka B, Fetzner S, Lingens F (1995) Quinoline 2-oxidoreductase and 2-oxo-1, 2-dihydroquinoline 5-6, dioxygenase from Comamonas testosterone 63: the first two enzymes in quinoline and 3-methylquinoline degradation. Eur J Biochem 232:536-544

3. Graves PR, Kwiek JJ, Fadden P, Ray R, Hardeman H, Coley AM, Foley M, Haystead TAJ (2002) Discovery of novel targets of quinoline drugs in the human purine binding proteome. Am Soc Pharmacol Exp Therapuetics Mol Pharmacol 62:1364-1372

4. Jianlong W, Liping H, Hanchang S, Yi Q (2001) Biodegradation of quinoline by gel immobilized Burkholderia sp. Chemosphere 44:1041-1046

5. Schwarz G (2005) Molybdenum cofactor biosynthesis and deficiency. Cell Mol Life Sci 62:2792-2810

6. Stephan I, Tshisuaka B, Fetzner F, Ltngbns F (1996) Quinaldine 4-oxidase from Arthrobactor sp. Ru4la, a versatile prokaryotic molybdenum-containing hydroxylase active towards $\mathrm{N}$-containing heterocyclic compounds and aromatic aldehydes. Eur J Biochem 236:155-162

7. Deeken UF, Goldenstedt B, Janßen RG, Kapp R, Huttermann J, Fetzner S (2003) Functional expression of quinoline 2-oxidoreductase genes (qorMLS) in Pseudomonas putida KT2440 pUF1 and in P. putida 86-1 Dqor pUF1 and analysis of the Qor proteins. Eur J Biochem 270:1567-1577

8. Hille R (1996) The mononuclear molybdenum enzymes. Chem Rev 96:2757-2816
9. Okamoto K, Matsumoto K, Hille R, Eger BT, Pai EF, Nishino T (2004) The crystal structure of Xanthine oxidoreductase during catalysis: implications for reaction mechanism and enzyme inhibition. Proc Nat Acad Sci. 101:7931-7936

10. Hille R (2006) Structure and function of Xanthine oxidoreductase. Eur J Inorg Chem 10:1913-1926

11. Schwarz G, Mendel RR, Ribbe MW (2009) Molybdenum cofactors, enzymes and pathways. Nature 460:839-847

12. Luisa CM, Eleonora E, Soledad GE, Barbara H, Alejandro TE (2011) The reaction electronic flux in chemical reactions. Sci China Chem 54(12):1982-1988

13. People JA et al (2004) Gaussian 03, revision C02 Gaussian, Inc. CT, Wallingford

14. Becke AD (1993) Density-functional thermochemistry. III. The role of exact exchange. J Chem Phys. 98:5648-5652

15. Hay PJ, Wadt WR (1985) Ab initio effective core potentials for molecular calculations. Potentials for the transition metal atoms Sc to Hg. J Chem Phys. 82:270-283

16. Contreras JG, Gerli LA (2008) Conformational preference in 4, 6-dimethyl-1, 3-thioxane. J Chil Chem Sci. 53:1400-1402

17. Gorelsky SI (2009). AOMix: Program for molecular orbital analysis; University of Ottawa http://www.sg-chem.net/

18. Gorelsky SI, Lever ABP (2001) Electronic structure and spectra of ruthenium diimine complexes by density functional theory and INDO/S. Comparison of the two methods. J Organomet Chem 635:187-196

19. Zhang XH, Wu YD (2005) A theoretical study on the mechanism of the reductive half-reaction of Xanthine oxiddase. Inorg Chem 44(5):1466-1471

20. Amano T, Ochi $N$, Sato $H$, Sakaki S (2007) Oxidation reaction by Xanthine oxidase. Theoretical study of reaction mechanism. J Am Chem Soc 129:8131-8138

\section{Submit your manuscript to a SpringerOpen ${ }^{\odot}$ journal and benefit from:}

- Convenient online submission

- Rigorous peer review

- Immediate publication on acceptance

- Open access: articles freely available online

- High visibility within the field

- Retaining the copyright to your article 